\title{
Differences in symptoms, functioning, and quality of life between women on long-term sick-leave with musculoskeletal pain with and without concomitant depression
}

\author{
This article was published in the following Dove Press journal: \\ Journal of Multidisciplinary Healthcare \\ 2 August 2011 \\ Number of times this article has been viewed
}

\author{
Gunilla Brodda Jansen ${ }^{1,2}$ \\ Jürgen Linder ${ }^{3}$ \\ Kristina Schüldt Ekholm ${ }^{4,5}$ \\ Jan Ekholm²,4 \\ 'Department of Pain Management, \\ Capio St Göran's Hospital, \\ ${ }^{2}$ Department of Clinical Sciences, \\ Division of Rehabilitation Medicine, \\ Karolinska Institutet, Danderyd \\ Hospital, ${ }^{3}$ Diagnostic Centre, Division \\ of Psychiatry, Department of Clinical \\ Neuroscience, Karolinska Institutet, \\ ${ }^{4}$ Stockholm Rehabilitation Medicine \\ University Clinic, Danderyd Hospital; \\ ${ }^{5}$ Section of Rehabilitation Science, \\ Department of Health Sciences, \\ Mid Sweden University, Campus \\ Östersund, Sweden
}

Objective: The aim was to describe the differences in symptoms, functioning and quality of life between women on long-term sick-leave due to protracted musculoskeletal pain with and without concomitant depression.

Design: Descriptive and comparisons with/without comorbid depression.

Methods: 332 female patients were examined by three specialist physicians in psychiatry, orthopedic surgery, and rehabilitation medicine and assigned to four groups according to the ICD-10 diagnoses: low back/joint disorders ( $\mathrm{LBJ}, \mathrm{n}=150)$, myalgia $(\mathrm{M}, \mathrm{n}=43)$, fibromyalgia (FM, $\mathrm{n}=87)$, or depression without somatic pain diagnosis ( $\mathrm{DE}, \mathrm{n}=52)$.

Results: Patients with somatic pain conditions LBJ, M, or FM showed more activity-related difficulties if concomitant depression was present during the activities 'focusing attention', 'making decisions', and 'undertaking a single task'; and in the domains 'energy level', 'memory functions', 'emotional functions', and 'optimism/pessimism'. Patients with FM and concomitant depression perceived higher pain intensity than patients in group DE. No statistically significant differences in physically related activities were noted between each of the somatic pain conditions with and without coexisting depression. FM patients with coexisting depression reported fewer painful sites on their pain drawings compared with FM-patients without depression. Patients with LBJ or FM and concomitant depression reported lower quality of life in the dimensions vitality, social functioning, emotional role, and mental health. Comorbid depression affected disability and restricted working capacity by reducing mental activity and functioning but not by affecting physical activity problems.

Conclusion: Women on long-term sick-leave, who have concomitant depression with LBJ or FM, also have more difficulties in focusing attention, making decisions, and carrying out tasks, and with memory functions and optimism/pessimism, as well as reduced quality of life in the dimensions of vitality, social functioning, emotional role, and mental health, than female patients without comorbid depression. As a consequence we suggest further efforts to integrate somatic and psychiatric interventions in the same rehabilitation program.

Keywords: chronic pain, depression, comorbidity, disability, sick-leave, quality of life

\section{Introduction}

Depression is a common comorbidity in somatic pain conditions. Comorbidity between somatic and psychiatric illness is one of the major factors influencing work disability and return to work rate, ${ }^{1-5}$ a common problem in several European countries. With this in mind, an attempt was made to investigate how comorbid depression influences
Correspondence: Jürgen Linder Hus 38, plan 3 Danderyds sjukhus, SE-182 87 Stockholm, Sweden Tel +46707292606 Email jurgen.linder@ki.se 
symptoms, functioning, and quality of life among patients with long-lasting musculoskeletal pain.

Long-lasting pain and depression are often coexisting diagnoses, and whether the depression is causing the pain or vice versa has been widely discussed. ${ }^{6}$ It has also been argued that the greater the severity of bodily pain, the less likelihood of remission of depression through anti-depressants. ${ }^{7}$ Furthermore, patients with concomitant depression and a diagnosed pain condition are often referred back and forth between psychiatric and somatic investigations, possibly increasing the suffering, prolonging sick leave, and further reducing functioning.

Depression per se can affect, and maybe reduce, the patient's rehabilitation capacity if not diagnosed and treated concomitantly with the somatic condition. As many as $80 \%$ of patients with psychiatric-somatic comorbidity referred to a multiprofessional assessment unit were assessed in need of medical or combined medical and vocational rehabilitation in order to resume work. ${ }^{4}$ Patients with this psychiatric-somatic comorbidity also need special attention for their treatment and rehabilitation. ${ }^{8,9}$ Other investigators have indicated that pain is strongly associated with psychiatric symptoms such as anxiety, depression, and chronic fatigue diagnoses; and that this kind of comorbidity affects physical outcome and functioning. ${ }^{10-13}$

Previously we have reported that four of the five most frequent combinations of ICD-10 diagnoses among patients on long-term sick-leave were FM/myalgia or spinal pain, in combination with depressive episode, recurrent depression, or anxiety. ${ }^{4}$ Furthermore, we have noted that patients with FM did not meet more criteria for personality disorders than patients with other somatic pain conditions but experienced more disabilities, most commonly in mobility and domestic-life areas. ${ }^{5}$ Because patients with FM were found not to have significantly more personality disorders than those with other types of chronic pain, personality was not considered as a confounding factor when studying depressive symptoms.

It may be relevant to study further the relationship between various measures and descriptors of pain with psychiatric disorders such as depression. The present study aimed to investigate the differences in symptoms, functioning, and quality of life between women on long-term sick-leave due to protracted musculoskeletal pain with and without comorbid depression. The study was based on multidisciplinary investigations resulting in ICD-10 diagnoses and assessment of work capacity in patients with difficulty in resuming work. The somatic diagnoses selected for the study were low-back/ joint disorders (LBJ), local myalgia (M) and FM and the psychiatric diagnoses were depressive episode and recurrent depression (DE) but without a somatic pain diagnosis.

\section{Materials and methods Patients}

Patients with long-term sick leave and with difficulties in returning to work were identified by local social insurance offices (SIO) in Stockholm County, Sweden, with a population of about 2 million people. SIO officials selected patients for multidisciplinary investigation and those who agreed were referred (2001-2007) to the Diagnostic Centre (DC) at the Karolinska Hospital in Stockholm at the cost of the SIO. The DC is a special unit for multidisciplinary diagnostics of somatic and psychiatric diseases and assessments of working ability. In total 635 patients were referred for multidisciplinary investigation and all were accepted. The aim was to establish ICD-10 diagnoses and prognoses, to assess further the patients' current disability status, to recommend possible medical, vocational, or combined medical/vocational rehabilitation, and to facilitate the patients' return to work. The individual results were sent to the referring SIO officers. All patient data were at the same time consecutively registered into a special research database in order to promote future research on these patients. ${ }^{14,15}$

\section{Clinical setting}

All patients were examined by three board-certified specialist physicians in psychiatry, orthopedic surgery, and rehabilitation medicine, respectively, at the DC, which specializes in multidisciplinary investigation of patients on long-term sickleave. The following procedures were used for all patients as part of the multidisciplinary evaluation:

\section{Patient history}

Data on social demographics such as education, social status, occupation, working conditions, and employment were collected with a 'patient history' structured form, especially constructed to provide optimal validity of the data collected.

\section{Symptoms and activities}

A form eliciting self-estimated difficulties with 18 activities and 16 symptoms/functions was constructed and linked to International Classification of Functioning (ICF) categories. ${ }^{16}$

\section{Psychiatric self-report questionnaires}

At their first visit, patients completed several psychiatric questionnaires and self-report scales. The Comprehensive Psychopathological Rating Scale for Self Administration (CPRS-SA), measuring 23 symptoms also including the Montgomery Åsberg Depression Rating Scale ${ }^{17}$ and the Depression Rating Self-report Questionnaire (DSRS), ${ }^{18}$ 


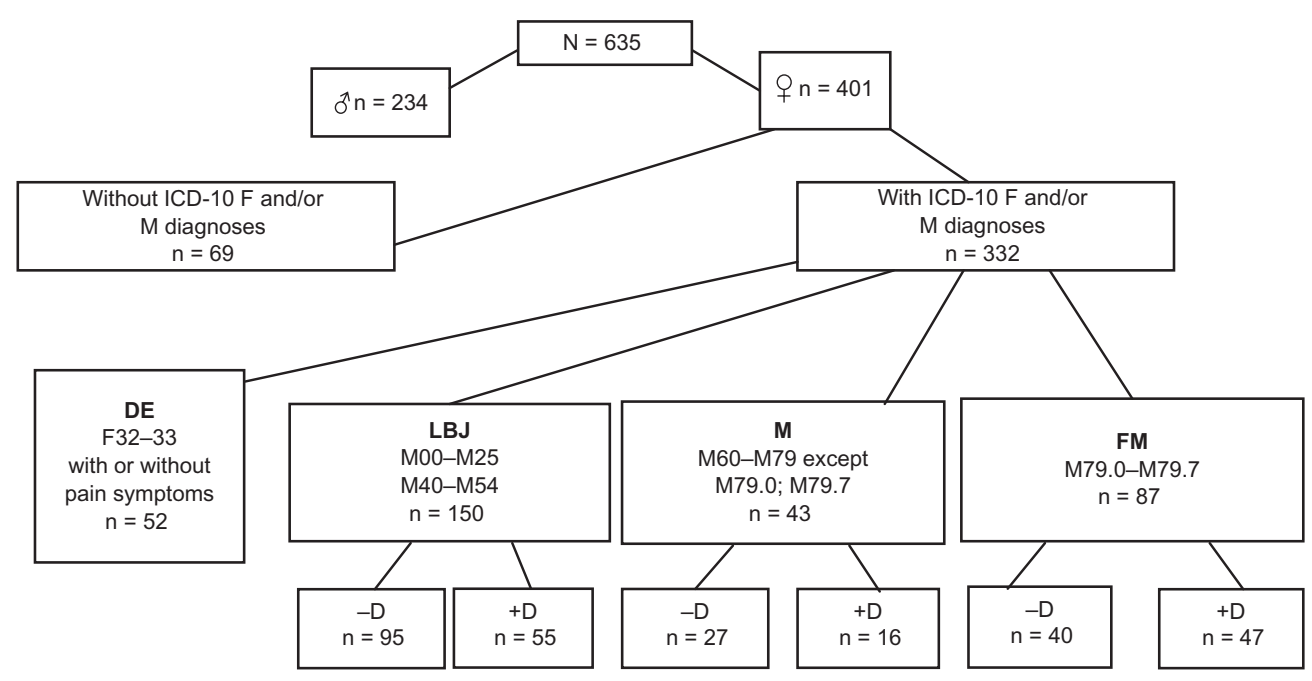

Figure I Flow chart showing the selection of 332 female patients.

Abbreviations: LBJ, low back/joint disorders; M, myalgia; FM, fibromyalgia; DE, depression; D, concomitant depression.

were used together with the Structured Clinical Interview for Diagnosis questionnaire SCID-II. ${ }^{19}$

\section{Quality of life}

The 36-item Health Survey (SF-36) was used to measure quality of life and well-being within 8 domains: 'Physical functioning' (PF), 'Role limitations' (RF) due to physical health problems, 'Bodily pain' (BP), 'Vitality' (V), 'General health' (GH), 'Social functioning' (SF), role limitations because of emotional problems (RE), and perceived 'Mental health' (MH). ${ }^{20,21}$

\section{Pain assessments}

Pain intensity was measured with a visual horizontal $100 \mathrm{~mm}$ analog scale (VAS) anchored with 0 as no pain and 100 as worst imaginable pain. VAS 'now' indicated present pain intensity, VAS 'worst' and VAS 'least' the worst and least pain intensity during the preceding two months. Pain intensity was further assessed with the pain item in the CPRS-SA.

\section{Pain drawings}

The patients indicated the location of pain on diagrams comprising 57 defined body regions. Twenty-three areas covered the neck-shoulder region, nine the lumbosacral-spine-thigh region, and twelve the knee-lower-leg-foot region. Categorization was based on the number of patients who marked each of the 57 areas as painful. ${ }^{22}$ In the analysis for the graphic presentations, the number of patients marking a certain area on the pain drawings was divided into three groups, according to the percentage of patients who had marked the particular areas: 0\%-33.99\% (green color); 34\%-66.99\% (yellow); 67\%-100\% (red) (see Figures 2-5).

\section{Clinical procedures}

Before their first visit the patients were informed by letter and later also by phone about the aim of the investigation. At the first visit to the DC, the patients received a third, repeated,

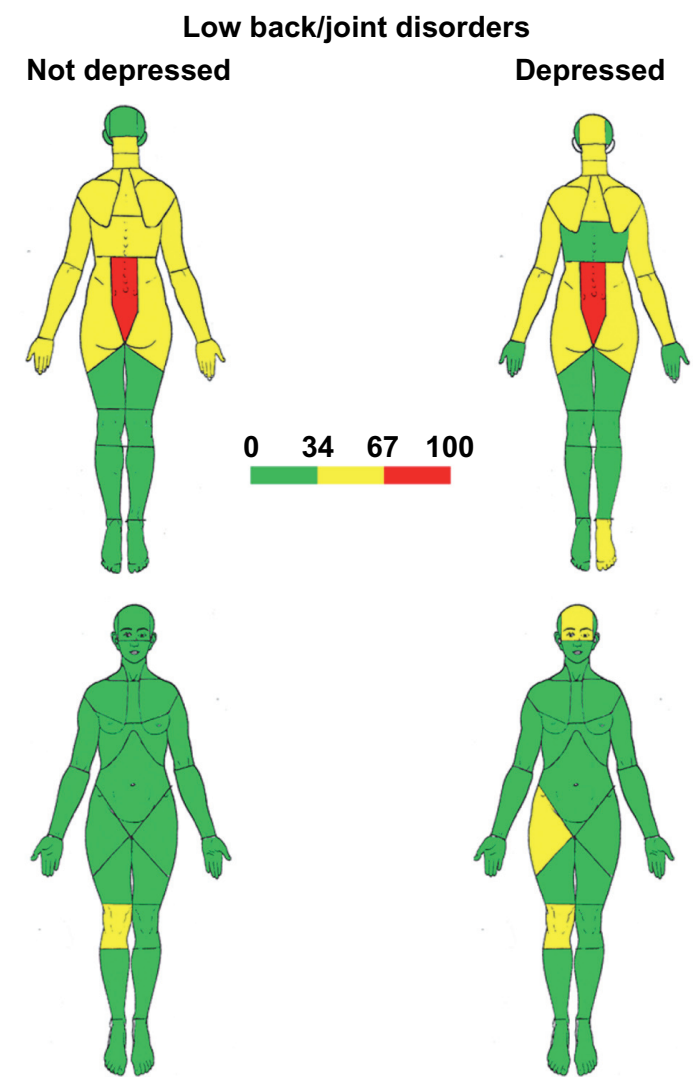

Figure 2 Percentage distribution of pain areas in patients with low back/joint disorders (LBJ) with and without concomitant depression.

Notes: The number of markings on the pain drawings are divided into three groups, according to the percentage of patients who had marked the particular areas: 0\%-33.99\% (green); 34\%-66.99\% (yellow); 67\%-100\% (red). 


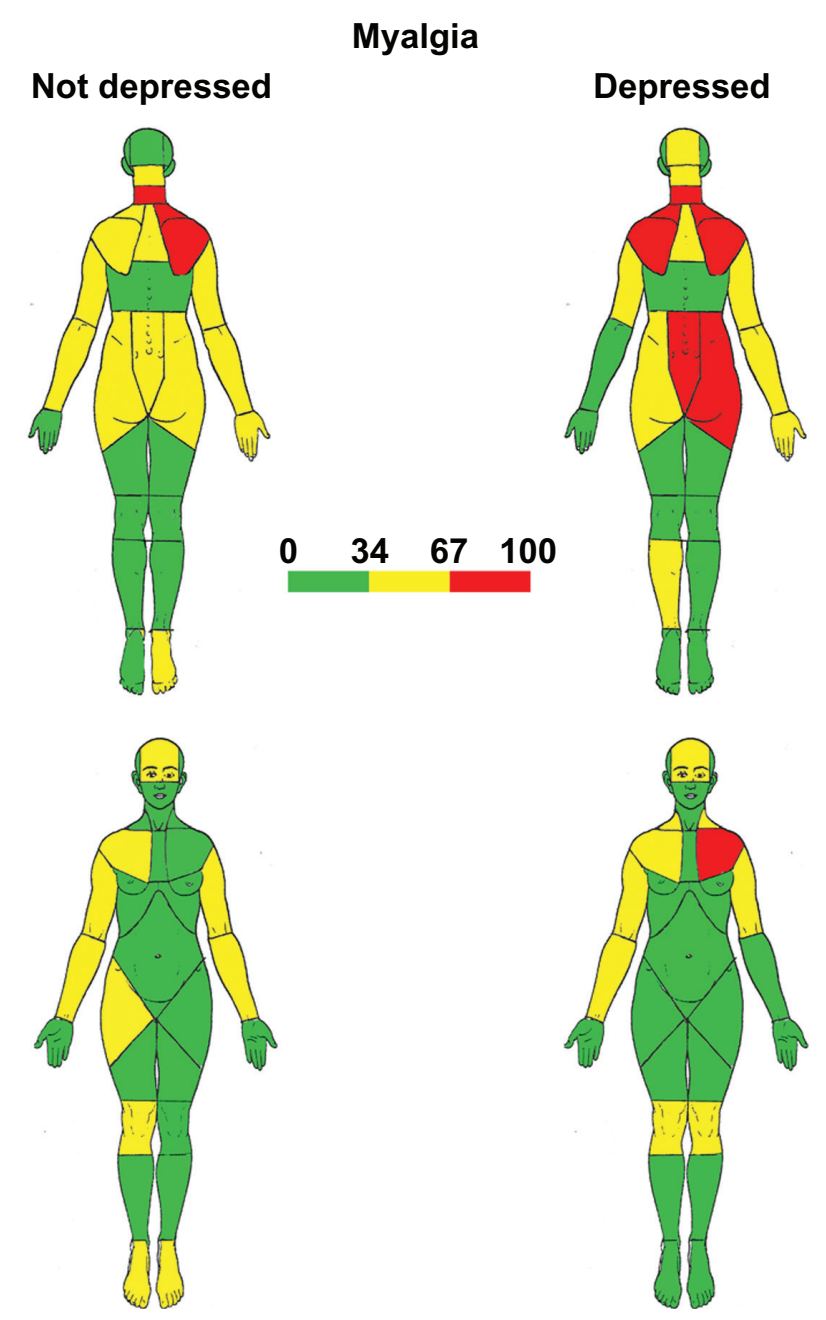

Figure 3 Percentage distribution of pain areas in patients with myalgia (M) with and without concomitant depression. See Figure 2.

set of information about the purpose of the investigation. They then filled out the questionnaires. They had continuous opportunity to ask the staff about the questionnaires.

Data from the questionnaires were immediately transferred to a $4 \mathrm{D}$ database ${ }^{14}$ before the clinical assessments. Individual protocols from this database were printed out and given to the physicians for their guidance and for validation.

Each patient was investigated during three separate visits within 3 weeks. At the first visit and after completing the questionnaires, patients underwent a full psychiatric evaluation by a board-certified psychiatrist who had access to the questionnaire results. The results of this investigation, the diagnoses, and the psychiatrist's assessment of the patient's current disability status, and recommendations for possible psychiatric rehabilitation, were documented in the patient's record.

At the patient's second visit, an orthopedic evaluation was performed by a board-certified orthopedic surgeon, who had access to the previous psychiatric record and to
Fibromyalgia
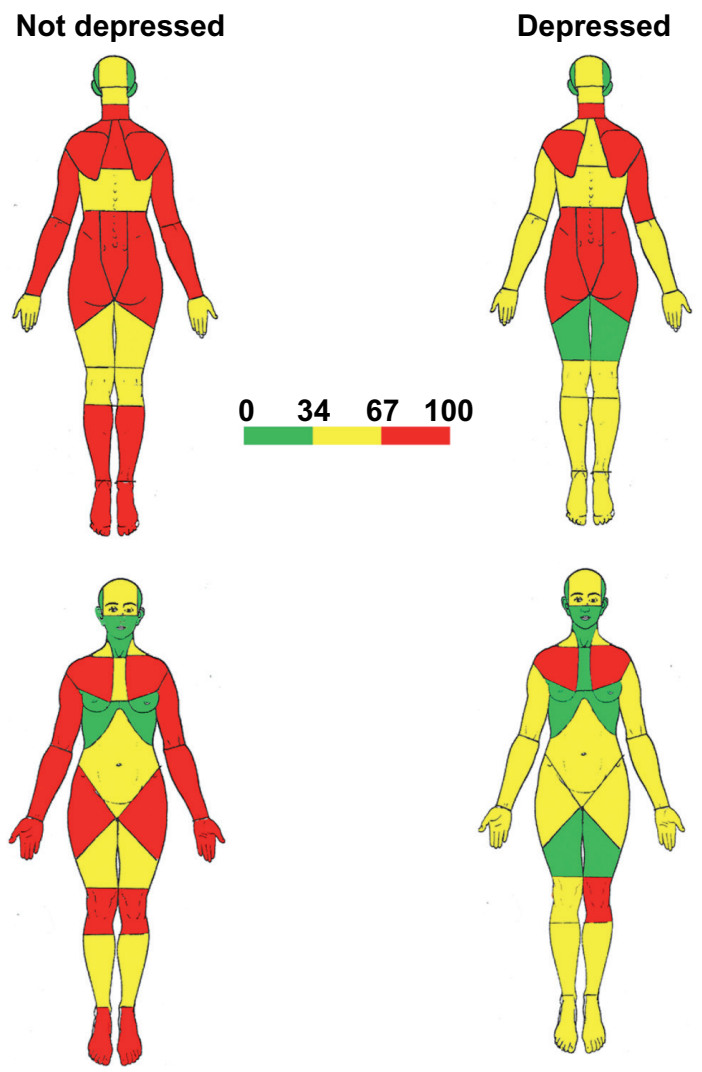

Figure 4 Percentage distribution of pain areas in patients with fibromyalgia (FM) with and without concomitant depression. See Figure 2.

previous orthopedic opinions and X-rays. The results of this second investigation (orthopedic diagnoses, current disability, rehabilitation recommendations) were documented as described above.

The patient's third visit comprised a full rehabilitationmedical investigation by a certified specialist physician in

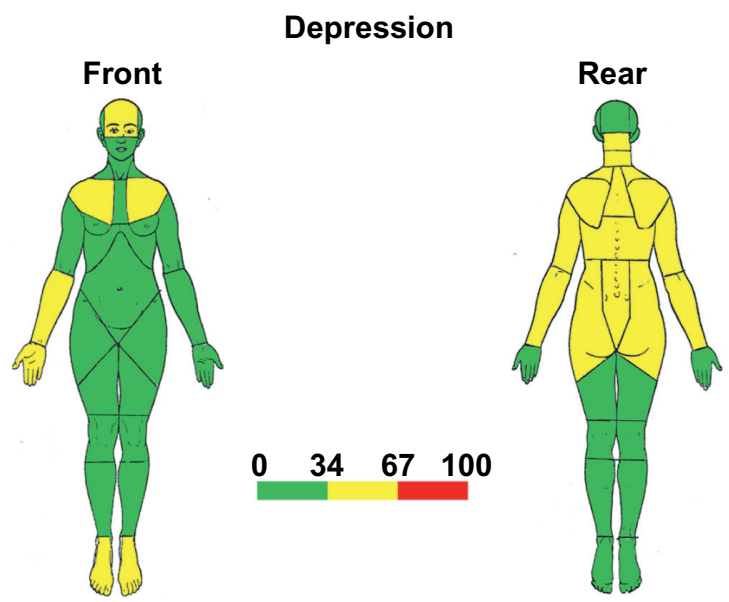

Figure 5 Percentage distribution of pain areas in patients with depression without somatic pain diagnoses (DE). See Figure 2. 
rehabilitation medicine who had access to all preceding information.

Finally, the results of the three consecutive evaluations were discussed for each patient with all three physicians present, resulting in a joint statement on diagnosis(es), degree, and duration of disability in regard to working capacity, and recommendations for possible rehabilitation measures. The individual statements were returned to the referring local social insurance office.

Since FM occurred predominantly in women, only women were included in the patient material for the present study, to make comparisons possible. Four groups of patients were selected for the study. The patients were assigned to the respective group according to the ICD-10 diagnoses given by the specialist physicians. The patients in the LBJ group were diagnosed with ICD-codes M00-M25 or M40-M54. Those in the $\mathrm{M}$ group were diagnosed with ICD-10 codes M60-M79 except FM M79.0 and M79.7. Patients with FM were diagnosed with ICD-codes M79.0 or M79.7. These three patient groups were sub-grouped according to presence or absence of concomitant depression. The fourth patient group comprised patients with ICD-diagnoses F32-33 Depression (DE). These patients could have symptoms of pain but had no somatic pain diagnoses made after the multidisciplinary investigation.

The initial number of multidisciplinarily investigated patients was 635. All male subjects, $n=234$, were excluded from the present study, as well as 69 female subjects with other diagnoses than LBJ, M, FM, or DE (or a few with incomplete questionnaires). The remaining 332 patients were included in this study (Figure 1, Table 1).

\section{Statistical methods}

We used nonparametric statistics, since most variables were of ordinal or binary character, or not normally distributed. For example VAS $=100 \mathrm{~mm}$ means having more pain than $\mathrm{VAS}=50 \mathrm{~mm}$, but this does not mean that VAS $=100$ is twice as much pain than VAS $=50$ and are in our opinion more adequately described as ordinal variables.

For comparisons across and between groups we used the Kruskal-Wallis test and Mann-Whitney $U$-test. In a first step the null hypothesis of the groups being equal was tested by Kruskal-Wallis test. If the null hypothesis was rejected, a second step with nine comparisons between the groups was made with the Mann-Whitney $U$-test. These comparisons were: (1) group DE was compared with all six remaining groups; (2) each of the three patient groups was compared with respect to presence or absence of concomitant depression. To control for false positive results due to mass significance, the Bonferroni correction was
Table I Patient characteristics

\begin{tabular}{lllll}
\hline $\begin{array}{l}\text { Diagnosis } \\
\text { group }\end{array}$ & $\mathbf{n}$ & $\begin{array}{l}\text { Percent of } \\
\mathbf{3 3 2} \text { patients }\end{array}$ & $\begin{array}{l}\text { Median age } \\
\text { in years }\end{array}$ & $\begin{array}{l}\text { Interquartile } \\
\text { range of age }\end{array}$ \\
\hline DE & 52 & 15.7 & 46.0 & $39.9-51.5$ \\
LBJ+D & 55 & 16.6 & 46.7 & $40.0-51.6$ \\
LBJ-D & 95 & 28.7 & 43.5 & $38.8-52.1$ \\
M+D & 16 & 4.9 & 44.4 & $38.2-48.0$ \\
M-D & 27 & 8.2 & 45.0 & $35.7-53.2$ \\
FM+D & 47 & 14.2 & 47.0 & $38.5-53.7$ \\
FM-D & 40 & 12.1 & 43.1 & $36.9-50.3$ \\
\hline
\end{tabular}

Notes: Diagnoses are depression without somatic pain diagnosis (DE), low back/ joint disorders (LBJ), myalgia (M), and fibromyalgia (FM). Presence or absence of comorbid depression is indicated by $+D$ and $-D$ respectively.

used, and $P<0.05$ was chosen as the level for statistically significant difference. Calculations were made using SPSS/PASW statistical program package (v 17; SPSS Inc, Chicago, IL).

\section{Pain descriptors}

As pain descriptors in the present study we used pain intensity VAS ratings (VAS now, VAS worst, VAS least), the pain item in the Comprehensive Psychopathological Rating Scale, ${ }^{23}$ and the patients' pain drawings. The SF-36 pain item is presented under health-related quality of life since this item concerns mainly how pain influences work activities.

\section{Ethical approval}

The study was approved by the Stockholm Regional Ethics Committee (DNR 95-149; 2006/1281-31; 2008/2-7). No informed consent from patients was needed because data were extracted from patient records. No patients were contacted for this study which is a follow-up from the patient registry. No patients can be identified in the results or the statistical calculations.

\section{Results}

\section{Pain intensity}

When comparing VAS now, VAS worst, and VAS least between patients in group DE and all patients in the three 'somatic' patient groups (LBJ, M, FM) with or without concomitant depression, patients with FM+D scored significantly higher than the reference patients in group DE by means of all pain descriptors used in this study. In addition, patients in group LBJ+D and FM-D scored higher than the reference group DE in the CPRS pain item (Table 2).

When we compared presence or absence of coexisting depression in each group, we did not note any significant differences for VAS now, VAS worst, VAS least, or CPRS pain item. However, there was a tendency in groups LBJ 
Table 2 Pain descriptors

\begin{tabular}{|c|c|c|c|c|c|c|c|c|}
\hline Pain descriptor & $\begin{array}{l}\text { DE } \\
n=52\end{array}$ & $\begin{array}{l}\text { LBJ-D } \\
n=95\end{array}$ & $\begin{array}{l}\text { LBJ+D } \\
n=55\end{array}$ & $\begin{array}{l}M-D \\
n=27\end{array}$ & $\begin{array}{l}M+D \\
n=16\end{array}$ & $\begin{array}{l}\text { FM-D } \\
n=40\end{array}$ & $\begin{array}{l}\text { FM+D } \\
n=47\end{array}$ & $\begin{array}{l}\text { Kruskal-Wallis } \\
P \text { value }\end{array}$ \\
\hline VAS now, mm & 50 & 50 & 50 & 50 & 50 & 67 & 70 & 0.002 \\
\hline Interquartile range & $23-70$ & $31-72$ & $40-75$ & $30-60$ & $30-75$ & $43-70$ & $56-70^{\dagger}$ & \\
\hline VAS worst, mm & 80 & 80 & 80 & 79 & 88 & 81 & 90 & 0.010 \\
\hline Interquartile range & $60-90$ & $60-90$ & $70-95$ & $69-89$ & $73-99$ & 77-99 & 80-99† & \\
\hline VAS least, mm & 30 & 30 & 40 & 20 & 37 & 31 & 50 & 0.002 \\
\hline Interquartile range & $|3-5|$ & $1 \mid-52$ & $20-69$ & $11-49$ & $19-54$ & 19-54 & $40-69^{\dagger}$ & \\
\hline Pain item CPRS & 2.0 & 2.0 & 2.5 & 2.1 & 2.0 & 2.2 & 2.5 & $<0.001$ \\
\hline Interquartile range & I.5-2.5 & I.5-2.5 & $2.0-3.0^{\dagger}$ & I.5-2.4 & $1.9-2.5$ & $2.0-3.0^{\dagger}$ & $2.1-3.0^{\dagger}$ & \\
\hline
\end{tabular}

Notes: †denotes significance $(P<0.05)$ difference from group DE. Median values and interquartile ranges of pain descriptors: VAS 'now', VAS 'worst', VAS 'least' (range 0-100 mm), and CPRS pain item (range 0-3) in 4 patient groups according to ICD-I0 diagnosis established by multidisciplinary investigation. Kruskal-Wallis test for independent samples across groups and Mann-Whitney $U$ test with Bonferroni correction were used for nine comparisons: between group DE and all other groups and group LBJ-D vs LBJ+D; M-D vs M+D; FM-D vs FM+D. Presence or absence of concomitant depression is denoted as $+D$ or $-D$ respectively.

Abbreviations: CPRS, Comprehensive Psychopathological Rating Scale; DE, depression without somatic pain diagnosis; LBJ, low back/joint disorders; M, myalgia; FM, fibromyalgia.

and $\mathrm{M}$ for patients with coexisting depression to report more intense pain than those without coexisting depression, although these differences, best seen in the interquartile ranges in Table 2, did not reach statistical significance, probably due to lack of power because of the relatively small sample sizes.

\section{Pain drawings}

The difference in spread of perceived pain of LBJ patients without and with concomitant depression is illustrated in Figure 2. More of the LBJ patients with concomitant depression had pain in the forehead and occipital head regions and in anterior hip and foot than did those without depression.

Among the M patients (Figure 3), more of those with concomitant depression marked pain in the occipital head region, left shoulder, lumbosacral spine region, and right posterior hip region than those without depression.

A different pattern from above was noted in patients with FM. Those with FM and no concomitant depression had more markings in the areas in the pain drawings than those with FM and co-existent depression (Figure 4). The FM-D patients marked the highest number of painful sites $(67 \%-100 \%)$ mainly in the upper left shoulder/upper thoracic spine, arms, palms, anterior hip regions, and lower legs/feet.

Depression (DE) with concomitant somatic ICD-10 diagnoses excluded can be seen as a reference (Figure 5). Fewer patients marked pain in the yellow areas (maximum $34 \%-67 \%$ ), located in the forehead, nape of the neck, shoulders, and posterior aspect of the rest of the trunk and arms. Thus the number of painful sites in patients with depression was lower than in those with FM without or with concomitant depression.

\section{Self-estimated difficulties with activities}

\section{Activities of a physical nature}

Table 3 illustrates the proportion of participants who perceived self-estimated difficulties with various activities of mainly physical nature. Comparisons can be made in two ways. (i) Using 'Depression without somatic pain diagnosis' (DE) as a reference helps when judging the magnitude of adding the somatic pain condition to the disability pattern in relation to 'depression without somatic pain diagnosis (DE)'. It indicates which particular activity is influenced by the comorbid depression. When comparing FM+D with $\mathrm{DE}$ we noted that patients diagnosed with FM+D had more difficulties with 'Household tasks' such as 'Peeling potatoes' (78.7\% vs $44.2 \%)$, 'Washing up by hand' (70.2\% vs $36.5 \%)$, 'Hanging washing up to dry' ( $89.4 \%$ vs $55.8 \%$ ), and 'Vacuuming' (91.5\% vs 63.5\%). For the domain 'Self-care', more patients in group FM+D compared with group DE had difficulties in items 'Washing hair' $(63.8 \%$ vs $32.7 \%)$ and 'Brushing hair' (59.6\% vs $28.9 \%$ ).

However, in the domain 'Mobility' more patients with FM+D indicated difficulties in only one item ie, turning one's head $(93.6 \%$ vs $57.7 \%)$ ). No further significant differences were noted for the other eight 'Mobility' items (Table 3).

In two activity limitations, 'carrying carrier bags with foodstuffs' and 'holding objects', significantly more patients with FM-D had difficulties than patients with DE. Also, when compared with patients with $\mathrm{DE}$ in the other five diagnosis groups, more patients tended to have difficulties in the domain 'Mobility' than the reference group DE. A general tendency was that more patients with FM reported difficulties with activities than the reference group DE.

(ii) The other way of making comparisons is to analyze how much co-existing depression 'adds' to the somatic 
Table 3 Percentage of self-estimated difficulties in activities (ICF category and diagnoses with and without concomitant depression, $+\mathrm{D}$ or $-\mathrm{D})$

\begin{tabular}{|c|c|c|c|c|c|c|c|c|c|}
\hline Activities & $\begin{array}{l}\text { ICF } \\
\text { category }\end{array}$ & $\begin{array}{l}\text { DE } \\
n=52\end{array}$ & $\begin{array}{l}\text { LBJ-D } \\
\mathrm{n}=95\end{array}$ & $\begin{array}{l}\text { LBJ+D } \\
\mathrm{n}=55\end{array}$ & $\begin{array}{l}M-D \\
n=27\end{array}$ & $\begin{array}{l}M+D \\
n=16\end{array}$ & $\begin{array}{l}\text { FM-D } \\
n=40\end{array}$ & $\begin{array}{l}F M+D \\
n=47\end{array}$ & $\begin{array}{l}\text { Kruskal- } \\
\text { Wallis } P\end{array}$ \\
\hline \multicolumn{10}{|l|}{ Mobility } \\
\hline Grasping objects & d 440I & 44.2 & 34.7 & 41.8 & 44.4 & 25 & 57.5 & 61.7 & 0.0234 \\
\hline Holding objects & d 4455 & 44.2 & 47.4 & 47.3 & 59.3 & 56.3 & $75.0^{\dagger}$ & 70.2 & 0.0093 \\
\hline Writing with pencil & d 4402 & 26.9 & 30.5 & 38.2 & 40.7 & 43.8 & 55 & 53.2 & 0.0244 \\
\hline Turning one's head & d 4108 & 57.7 & 69.5 & 74.5 & 55.6 & 62.5 & 77.5 & $93.6^{\dagger}$ & 0.0017 \\
\hline $\begin{array}{l}\text { Carrying carrier bags } \\
\text { with foodstuffs }\end{array}$ & d 430I & 76.9 & 89.5 & 94.5 & 85.2 & 87.5 & $97.5^{\dagger}$ & 93.6 & 0.0262 \\
\hline Going by car as passenger & d 470I & 25.0 & 47.4 & 25.5 & 25.9 & 31.3 & 50 & 51.1 & 0.0050 \\
\hline Driving a car & d 475I & 44.2 & 40.0 & 36.4 & 40.7 & 25 & 42.5 & 38.3 & 0.8796 \\
\hline Going by bus & d 4702 & 51.9 & 51.6 & 40.0 & 33.3 & 43.8 & 65 & 61.7 & 0.0701 \\
\hline Going by train & d 4702 & 44.2 & 44.2 & 36.4 & 29.6 & 31.3 & 67.5 & 59.6 & 0.0078 \\
\hline \multicolumn{10}{|l|}{ Self-care } \\
\hline Washing hair & d 5100 & 32.7 & 35.8 & 47.3 & 40.7 & 43.8 & $70^{\dagger}$ & $63.8^{\dagger}$ & 0.0007 \\
\hline Combing hair & d 5202 & 30.8 & 25.3 & 41.8 & 25.9 & 18.8 & 57.5 & 55.3 & 0.0004 \\
\hline Brushing hair & d 5202 & 28.9 & 27.4 & 40 & 25.9 & 31.3 & 62.5 & $59.6^{\dagger}$ & 0.0008 \\
\hline \multicolumn{10}{|l|}{ Household tasks } \\
\hline Peeling potatoes & d 6300 & 44.2 & 57.9 & 56.4 & 74.1 & 56.3 & $90.0^{\dagger}$ & $78.7^{\dagger}$ & $<0.0001$ \\
\hline Washing up by hand & d 6401 & 36.5 & 47.4 & 56.4 & 63.0 & 63.0 & $77.5^{\dagger}$ & $70.2^{\dagger}$ & 0.0008 \\
\hline Picking up objects from floor & d 6402 & 46.2 & 60.0 & 67.3 & 44.4 & 68.8 & 75.0 & 72.3 & 0.0195 \\
\hline Hanging washing up to dry & $d 6400$ & 55.8 & 76.8 & 74.5 & 70.4 & 81.3 & $90.0^{\dagger}$ & $89.4^{\dagger}$ & 0.0015 \\
\hline Vacuuming & d 6403 & 63.5 & $84.2^{\dagger}$ & $81.8^{\dagger}$ & 77.8 & 87.5 & $95^{\dagger}$ & $91.5^{\dagger}$ & 0.0019 \\
\hline
\end{tabular}

Notes: ${ }^{\dagger}$ denotes significance $P<0.05$ in comparison with Group DE. Kruskal-Wallis test for independent samples across groups and Mann-Whitney $U$ test with Bonferroni correction were used for 9 comparisons: between-group $D E$ and all other groups and group LBJ-D vs LBJ+D; M-D vs M+D; FM-D vs FM+D. Presence or absence of concomitant depression is denoted as $+D$ or $-D$ respectively.

Abbreviations: DE, depression without somatic pain diagnosis; ICF, International Classification of Functioning; LBJ, low back/joint disorders; M, myalgia; FM, fibromyalgia.

pain condition, regarding the proportion of patients perceiving difficulties in various activities. The somatic pain conditions are presented as columns without comorbid depression (-D) and with comorbid depression (+D). No consistent or significant differences in activity-related difficulties were noted between each of the somatic pain conditions without co-existing depression (LBJ-D, M-D, FM-D) and each of those with depression as comorbidity $(\mathrm{LBJ}+\mathrm{D}, \mathrm{M}+\mathrm{D}, \mathrm{FM}+\mathrm{D})$. This comparison indicates that adding depression as comorbidity to the long-lasting somatic pain conditions has little or no effect on disability in the mainly physical domains mobility, self-care, and household tasks (Table 3).

\section{Activities/functions of a mental character}

For the three somatic groups, ie, the somatic conditions LBJ, M, or FM, pair-wise comparisons (-D vs $+\mathrm{D})$ of difficulties at the ICF activity level in the domain of 'applying knowledge' and 'carrying out tasks', showed significantly more difficulty if depression was present as comorbidity regarding 'focusing attention', 'making decisions' and 'undertaking a single task' ( $-\mathrm{D}$ and $+\mathrm{D}$ in Table 4, upper).
In these domains we also noted a significant difference between the DE group with each of the other groups without coexisting depression (LBJ-D, M-D, FM-D). No differences were noted when comparing group DE with the somatic groups with coexisting depression $(\mathrm{LBJ}+\mathrm{D}, \mathrm{M}+\mathrm{D}, \mathrm{FM}+\mathrm{D}$.

At the ICF level of physiological/psychological functions (Table 4, lower part) pair-wise (-D vs $+\mathrm{D})$ differences were found in the domains: 'energy level'(LBJ), 'memory functions' (LBJ and FM), and 'optimism/pessimism' (LBJ and FM). In all domains, patients with concomitant depression had more difficulties than those in the same diagnosis group but without depression. A majority of these differences reached statistical significance after the Bonferroni correction (Table 4). Also, patients with somatic diagnoses but without concomitant depression had fewer difficulties than patients with depression and no somatic diagnosis (group DE). The somatic patients with concomitant depression $(\mathrm{LBJ}+\mathrm{D}, \mathrm{M}+\mathrm{D}$, FM+D) reported similar difficulties to patients in group DE. The general trend noted in Table 4 was that patients with somatic diagnoses but without concomitant depression had fewer difficulties in the investigated ICF domains compared with the reference group DE. Exceptions were fatigability and reduced sleep in the FM-D group. 
Table 4 Self-estimated difficulties in activities (ICF category (WHO 200I) and diagnoses with and without concomitant depression, $+\mathrm{D}$ or $-\mathrm{D})$

\begin{tabular}{|c|c|c|c|c|c|c|c|c|c|}
\hline $\begin{array}{l}\text { ICF category } \\
\text { and number }\end{array}$ & $\begin{array}{l}\text { CPRS item (original } \\
\text { number and name) }\end{array}$ & $\begin{array}{l}D E \\
n=52\end{array}$ & $\begin{array}{l}\text { LBJ-D } \\
n=95\end{array}$ & $\begin{array}{l}\text { LBJ+D } \\
n=55\end{array}$ & $\begin{array}{l}M-D \\
n=26\end{array}$ & $\begin{array}{l}M+D \\
n=16\end{array}$ & $\begin{array}{l}\text { FM-D } \\
n=40\end{array}$ & $\begin{array}{l}F M+D \\
n=46\end{array}$ & $\begin{array}{l}\text { Kruskal- } \\
\text { Wallis } P\end{array}$ \\
\hline \multicolumn{10}{|c|}{ ICF-activity level: Applying knowledge } \\
\hline Focusing attention & 16. Concentration & 1.8 & 1.0 & 1.5 & 0.8 & 1.8 & 1.0 & 2.0 & $<0.0001$ \\
\hline d I 60 & difficulties & $1.0-2.4$ & $0.0-1.6^{\dagger}$ & $1.0-2.2$ & $0.0-1.5^{\dagger}$ & $1.0-2.2$ & $0.0-1.9^{\dagger}$ & $1.5-2.5$ & \\
\hline Making decisions & 13. Indecision & 1.4 & 0.0 & 1.0 & 0.0 & 1.0 & 0.0 & 1.5 & $<0.0001$ \\
\hline d 177 & & $0.7-2.0$ & $0.0-1.0^{\dagger}$ & $0.5-2.0$ & $0.0-1.0^{+}$ & $0.7-1.9$ & $0.0-1.0^{+}$ & $1.0-2.0$ & \\
\hline \multicolumn{10}{|l|}{ Carrying out tasks } \\
\hline Undertaking a single task & 14. Lassitude & 2.0 & 1.0 & 2.0 & 1.0 & 2.0 & 1.5 & 2.0 & $<0.000$ I \\
\hline d 210 & & $1.0-2.5$ & $0.0-1.5^{\dagger}$ & I.I-2.5 & $0.5-1.6^{\dagger}$ & I.0-2.3 & $0.5-2.0^{\dagger}$ & $1.9-2.1$ & \\
\hline \multicolumn{10}{|c|}{ ICF -physiological/psychological functions level } \\
\hline Energy level & 15. Fatigability & 2.1 & 2.0 & 2.0 & 1.3 & 2.0 & 2.0 & 2.1 & $<0.0001$ \\
\hline b 1300 & & $2.0-2.5$ & $1.0-2.0^{\dagger}$ & $1.5-2.4$ & $0.4-2.0^{\dagger}$ & $1.1-2.5$ & $1.5-2.0$ & $2.0-2.5$ & \\
\hline Memory functions & I7. Failing memory & 2.0 & 1.0 & 1.5 & 0.5 & 1.0 & 1.0 & 2.0 & $<0.0001$ \\
\hline b 144 & & $1.1-2.0$ & $0.0-1.5^{\dagger}$ & $1.0-2.0$ & $0.0-1.2^{\dagger}$ & $0.1-1.9$ & $0.0-2.0^{\dagger}$ & $1.1-2.2$ & \\
\hline Decreased sleep & 19. Reduced sleep & 2.0 & 1.5 & 2.0 & I.I & 2.0 & 2.0 & 2.0 & $<0.0001$ \\
\hline b 134 & & I.I-2.5 & $0.5-2.0^{\dagger}$ & $1.0-2.0$ & $0.4-2.0^{\dagger}$ & $1.0-2.1$ & $1.5-2.5$ & $2.0-2.5$ & \\
\hline Emotional functions & I. Sadness & 1.5 & 0.5 & 1.5 & 0.5 & 1.0 & 0.5 & 2.0 & $<0.0001$ \\
\hline b 152 & & $1.0-2.4$ & $0.0-1.0^{\dagger}$ & $1.0-2.1$ & $0.0-1.0^{\dagger}$ & $0.5-2.1$ & $0.0-1.0^{\dagger}$ & $1.0-2.5$ & \\
\hline Optimism/pessimism & 6. Pessimistic & 1.8 & 0.5 & 1.8 & 0.8 & 1.3 & 0.5 & 1.9 & $<0.0001$ \\
\hline b 1265 & thoughts & I.3-2.I & $0.0-1.4^{\dagger}$ & $1.0-2.1$ & $0.4-1.6^{\dagger}$ & $0.5-2.2$ & $0.0-1.4^{\dagger}$ & I.0-2.4 & \\
\hline
\end{tabular}

Notes: tdenotes significant $(P<0.05)$ difference from group DE. Bold numbers in columns indicate significant difference between the same diagnosis groups with and without depression. Median values and interquartile range of each item, graded 0 to 3 according to increasing severity. $(0=$ no symptoms, $3=$ maximal symptom intensity). Kruskal-Wallis test for independent samples across groups and Mann-Whitney $U$ test with Bonferroni correction were used for nine comparisons: between-group DE and all other groups and group LBJ-D vs LBJ+D; $M-D$ vs $M+D$; FM-D vs FM+D. Presence or absence of concomitant depression is denoted as $+D$ or $-D$ respectively.

Abbreviations: DE, depression without somatic pain diagnosis; LBJ, low back/joint disorders; M, myalgia; FM, fibromyalgia.

\section{Health-related quality of life (SF-36)}

Figure 6 shows the $T$ scores of all eight dimensions of the SF-36 for patients with depression without somatic diagnoses (DE) and for each of the three somatic diagnosis groups with concomitant depression (LBJ+D, M+D, FM+D) (red) and patients without concomitant depression (LBJ-D, M-D, FM-D) (blue). Note that, for the four health-related quality dimensions, 'Physical functioning' (PF), 'Physical role' (PR), 'Bodily pain' (BP), and 'General health' (GH), there was no difference from the reference group $\mathrm{DE}$ or between each of the diagnosis groups in regard to 'with depression' and 'without depression'.

However, LBJ, M, and FM patients without depression had significantly higher health-related quality of life in the dimensions 'Emotional role' (ER) and 'Mental health' (MH) compared with the reference group DE as well as with those in the same diagnosis group with concomitant depression.

Table 5 shows that for the dimensions 'Vitality' (V), and 'Social functioning' (SF), patients in groups LBJ-D and

Table 5 Medians of T scores of health related quality of life (SF-36) in four patient groups

\begin{tabular}{lllllllll}
\hline & DE & LBJ-D & LBJ+D & M-D & M+D & FM-D & FM+D & Kruskal-Wallis P \\
\hline Physical functioning & 33.6 & 30.3 & 24.7 & 33.4 & 23.4 & $20.0^{\dagger}$ & $20.0^{\dagger}$ & $<0.0001$ \\
Role physical & 22.4 & 22.4 & 22.4 & 22.4 & 22.4 & 27.6 & 22.4 & 0.1284 \\
Bodily pain & 35.2 & 33.5 & 31.2 & 34.2 & 33.5 & $30.1^{\dagger}$ & $30.6^{\dagger}$ & 0.0020 \\
General health & 29.7 & 32.3 & 30.0 & 32.3 & 30.7 & 27.4 & $25.6^{\dagger}$ & $<0.0001$ \\
Vitality & 26.4 & $\mathbf{3 4 . 7 ^ { \dagger }}$ & $\mathbf{2 8 . 3}$ & $32.7^{\dagger}$ & 27.9 & $\mathbf{2 7 . 7}$ & $\mathbf{2 4 . 3}$ & $<0.0001$ \\
Social functioning & 25.6 & $\mathbf{3 3 . 6 ^ { \dagger }}$ & $\mathbf{2 5 . 6}$ & $33.6^{\dagger}$ & 30.6 & $\mathbf{3 1 . 7}$ & $\mathbf{2 2 . 5}$ & $<0.0001$ \\
Role emotional & 20.8 & $\mathbf{4 3 . 6 ^ { \dagger }}$ & $\mathbf{2 0 . 8}$ & $\mathbf{4 5 . I ^ { \dagger }}$ & $\mathbf{2 0 . 8}$ & $\mathbf{4 9 . I ^ { \dagger }}$ & $\mathbf{2 0 . 8}$ & $<0.0001$ \\
Mental health & 26.0 & $\mathbf{4 5 . 6}^{\dagger}$ & $\mathbf{2 8 . 0}$ & $\mathbf{4 1 . 2 ^ { \dagger }}$ & $\mathbf{2 8 . 3}$ & $\mathbf{4 4 . 8}^{\dagger}$ & $\mathbf{2 2 . 8}$ & $<0.0001$ \\
\hline
\end{tabular}

Notes: ${ }^{t}$ denotes significant $(P<0.05)$ difference from group DE. Bold numbers indicate significant $(P<0.05)$ difference between the same diagnosis groups with and without depression. Presence or absence of concomitant depression is denoted $+D$ or $-D$. T score 50 corresponds to the Swedish norm for healthy individuals controlled for age and gender. ${ }^{19}$ Kruskal-Wallis test for independent samples across groups and Mann-Whitney $U$ test with Bonferroni correction were used for comparisons between group $D E$ and all other groups and LBJ-D vs LBJ+D; M-D vs M+D; FM-D vs FM+D.

Abbreviations: DE, depression without somatic pain diagnosis; LBJ, low back/joint disorders; M, myalgia; FM, fibromyalgia. 
M-D had significantly higher quality of life than patients in group DE.

In these dimensions, $\mathrm{V}$ and SF, patients without concomitant depression had higher quality of life than patients with concomitant depression within the same patient group (LBJ, FM). A similar difference was noted in group $M$ but did not reach significance.

In the domains 'Emotional role' (ER), and 'Mental health' $(\mathrm{MH})$, patients with somatic diagnoses without coexistent depression had significantly higher quality of life than patients in the reference group DE. When comparing each of the somatic groups (LBJ, M, FM) with respect to coexisting depression (-D vs $+\mathrm{D})$, those with coexisting depression had significantly lower quality of life in all groups, comparable to the quality of life of the reference group DE in these domains (Table 5; Figure 6).

In SF-36, a lower T score for bodily pain and physical functioning means that pain interferes more with normal work, including work outside the home and housework. Bodily pain and physical functioning in SF-36 (Table 5) showed lower values and thus more interference in FM patients with or without concomitant depression than in those with depression only.

\section{Rehabilitation recommendations}

Only a few patients, from $0 \%$ to about $5 \%$ in the different diagnosis groups, were recommended to return to work without further rehabilitation (Table 6). More than $80 \%$ of patients needed some interventions, most commonly medical or combined medical and vocational rehabilitation.

Of the patients with FM without concomitant depression, $20 \%$ were assessed as lacking current or future working capacity, whereas in those with FM and concomitant depression only about $10 \%$ were judged to lack current or future working capacity. Fewer LBJ+D and FM+D patients $(5.5 \%$ and $6.4 \%$ ) were recommended direct vocational rehabilitation compared with LBJ and FM without depression (30.9\% and $12.5 \%$ ). Instead, more of the ' $+\mathrm{D}$ ' patients were recommended medical rehabilitation, and more nondepressed patients were recommended direct vocational rehabilitation without further medical rehabilitation (Table 6).

More patients with comorbid depression were recommended medical rehabilitation than those without depression. The team assessment of the patients' disability/incapacity pension did not depend on the presence of concomitant depression.

\section{Discussion}

A major conclusion in the present study is the difference in self-rated disabilities in patients with somatic pain conditions of musculoskeletal origin with respect to concomitant depression.

Our results show that patients with LBJ or FM and concomitant depression have more difficulties in concentration, indecision, and lassitude, or expressed as ICF activity categories 'focusing attention', 'making decisions' and 'carrying out tasks' (Table 4). Furthermore, patients of the LBJ+D group and FM+D group with comorbid depression had more difficulties than those without coexisting depression with failing memory and pessimistic thoughts and, in addition, LBJ+D patients had more difficulties with fatigability (in ICF terms impairment of energy level). However, depression as comorbidity to LBJ, M, or FM did not affect self-reported disability of a physical character. These are all factors and activities important for working ability that may have contributed to the referral of these patients from the Social Insurance Offices (SIO) due to difficulties to resume work. The results indicate that comorbid depression with these somatic pain conditions reduces important abilities of mental but not of physical character.

Table 6 Rehabilitation recommendations for all groups and subgroups

\begin{tabular}{|c|c|c|c|c|c|c|c|}
\hline & $\begin{array}{l}\text { DE } \\
n=52\end{array}$ & $\begin{array}{l}\text { LBJ-D } \\
\mathrm{n}=94\end{array}$ & $\begin{array}{l}\text { LBJ+D } \\
n=55\end{array}$ & $\begin{array}{l}\text { M-D } \\
n=27\end{array}$ & $\begin{array}{l}M+D \\
n=16\end{array}$ & $\begin{array}{l}\text { FM-D } \\
n=40\end{array}$ & $\begin{array}{l}\text { FM+D } \\
n=47\end{array}$ \\
\hline BW & 0 & 5.3 & 3.6 & 3.7 & 0 & 0 & 2.1 \\
\hline V & 7.7 & 30.9 & 5.5 & 18.5 & 12.5 & 12.5 & 6.4 \\
\hline MV & 40.4 & 35.1 & 36.4 & 29.6 & 31.3 & 27.5 & 23.4 \\
\hline$M$ & 42.3 & 17.0 & 41.8 & 44.4 & 50.0 & 40.0 & 57.5 \\
\hline DP & 9.6 & II.7 & 12.7 & 3.7 & 6.3 & 20.0 & 10.6 \\
\hline $\begin{array}{l}\text { Summary of all rehabilitation } \\
\text { recommendations }(\mathrm{V}+\mathrm{MV}+\mathrm{M})\end{array}$ & 90.4 & 83.0 & 83.7 & 92.5 & 93.8 & 80.0 & 87.3 \\
\hline
\end{tabular}

Notes: Percentage distribution of rehabilitation recommendations within each of 7 patient groups. Presence or absence of concomitant depression is denoted as $+D$ or $-D$. Rehabilitation recommendations: Back to work without rehabilitative measures (BW), Vocational Rehabilitation (V), combined Medical and Vocational rehabilitation (MV), Medical rehabilitation (M). Disability pension (DP). Kruskal-Wallis test for independent samples across groups detected not significant $(P<0.05)$ differences across the 7 patient groups. Abbreviations: DE, depression without somatic pain diagnosis; LBJ, low back/joint disorders; M, myalgia; FM, fibromyalgia. 
The same tendency was noted in the patients with myalgia (M), but the small number of patients in this group: 16 patients with and 26 patients without comorbid depression reduces the statistical power in addition to the conservative statistics we have used in this study.

A quite different aspect is that more patients of the FM group, both with and without comorbid depression had more difficulties with self-care and household tasks than the reference group DE, consisting of patients diagnosed with depression but not with somatic diagnoses.

As a general aspect, the somatic patients with concomitant depression (LBJ+D, M+D, FM+D) reported similar difficulties in activities of physical and mental character as patients in group DE. The general trend noted in Table 4 was that patients with somatic diagnoses but without concomitant depression had fewer difficulties in the investigated ICF domains compared with the reference group DE. Exceptions were fatigability and reduced sleep in the FM-D group.

Conversely, there were no differences demonstrated regarding ICF activities between the patient groups with coexistent depression and the reference group DE. This can be interpreted as the depressive 'shadow' overriding the impairment of functions and activities caused by the underlying pain.

For all three somatic diagnosis groups studied, coexisting depression is associated with a lower quality of life in various dimensions (for LBJ and FM): 'Vitality', 'Social functioning', 'Emotional role', 'Mental health', and for M: 'Emotional role' and 'Mental health' (Figure 6 and Table 5). However, for the more 'somatic' dimensions: 'Physical functioning', 'Physical role', 'Bodily pain' and 'General health' there was no difference demonstrated whether patients were diagnosed with comorbid depression or not. This would indicate that coexisting depression decreases health-related quality of life in socially, emotionally, and mentally related dimensions but probably not in physical dimensions and pain.

In a study by Ahrens et al, ${ }^{24}$ a difference was reported in the quality of life (SF-36) between patients with comorbid depression to low back pain and without depression. They reported lower scores for 'Bodily pain', 'General health', 'Vitality', 'Social functioning', 'Emotional role function', and 'Mental health' in the SF-36.

So there is agreement on the influence on vitality, social functioning, emotional role, and mental health but not on bodily pain and general health, probably due to differences in the selection of the patients.

The present results have a bearing on rehabilitation. Previous studies show a positive association between pain

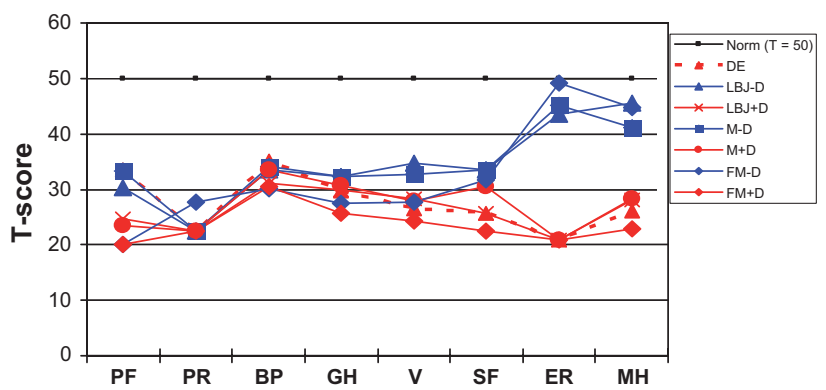

Figure 6 SF-36 health related quality of life in patients with low back/joint disorders (LBJ), myalgia, (M), fibromyalgia (FM), with and without concomitant depression $(+D,-D)$ and patients with depression without somatic pain diagnoses (DE). Presented as $T$-scores where $T=50$, according to the statistical Swedish norm controlled for age and gender.

Abbreviations: PF, physical functioning; RF, role limitations due to physical health problems; BP, bodily pain; V, vitality; GH, general health perception; SF, social functioning; RE, role limitations because of emotional problems; ME, perceived mental health.

and depression, ${ }^{7,8,12,25}$ regarding both mental and physical symptoms. This association is not really confirmed in the present study. Our study indicates that comorbid depression affects disability and reduces working ability not by affecting physical activity problems, but by reducing the mental activity and function. This is important to take into account when designing and performing rehabilitation interventions for patients with somatic pain diagnoses and comorbid depression. In many rehabilitation settings this is not specifically addressed. A prerequisite for successful outcome of rehabilitation programs may instead be to address the somatic and psychiatric interventions in combination. This has also recently been addressed by Wang et al, ${ }^{26}$ Fuller-Thomson et al, ${ }^{27} \mathrm{Hall}$ et al, ${ }^{28}$ and Reme et al. ${ }^{29}$ But the enigma remains: few rehabilitation centers today offer interventions for both pain and the mental disorders such as depression.

The questions behind the SF-36 in dimension 'Social functioning' include problems with remunerative employment and leisure time, which can be interpreted as important factors for work resumption after the illness. Also, reduced vitality implies lack of energy, which can be an obstacle to work resumption.

One question was whether pain intensity was increased in patients with a somatic pain diagnosis and concomitant depression. The results show that FM-patients with concomitant depression perceive more pain compared with the reference group (DE) in terms of CPRS pain item score and also in all three VAS measures (VAS now, VAS worst, VAS least).

One of the aims of this study was to compare symptoms and pain in patients with localized or generalized pain states, with respect to concomitant depression. Recent studies have 
reported that comorbid depression was associated with higher prevalence of painful physical symptoms. ${ }^{30,31} \mathrm{~A}$ recent study of 370 patients noted that pain characteristics such as number of pain sites, pain duration, pain intensity, and pain interference were all significantly associated with psychiatric morbidity. ${ }^{32}$ It has also been reported that more than half of the patients with depression in a primary care setting reported pain as the major somatic complaint. ${ }^{25}$

The findings in the present study that perceived clinical pain intensity is probably unaffected by the existence of comorbid depression was unexpected and would contribute to a better understanding of the complex interaction between pain and depression.

Patients with depression and LBJ or $\mathrm{M}$ reported more spread pain than patients without coexisting depression as demonstrated in Figures 2-5. However, the differences were of a moderate degree.

An unexpected finding was that patients diagnosed with both widespread pain (FM) and coexisting depression reported fewer painful sites in terms of areas marked on their pain drawings (Figure 3), than patients diagnosed with FM without depression. Many of the studies mentioned above indicate that patients with depression compared to patients without depression have significantly higher pain thresholds than healthy controls, but report more frequent pain sites and more intense pain, when pain is experimentally induced. ${ }^{33,34}$ Few reports, however, discuss clinical pain in depressed patients and the results diverge. A 1965 study by Merskey, ${ }^{35}$ demonstrated that patients with depression and concomitant pain had lower pressure-pain thresholds than patients without pain, which could indicate a difference between clinical pain and pain sensitivity. Other studies have shown that patients with depression and pain report more pain, both intensity and duration. ${ }^{25,36,37}$

Our patients reported the number of painful sites on a pain drawing and no testing of pain sensitivity was performed. Yet for patients with widespread pain such as FM it seems that comorbid depression could be a factor decreasing pain expression in terms of degree of spread. One plausible explanation could be that depression makes the patient reluctant to feel and report pain, thereby not marking it on a pain drawing. However, this significant difference was seen only in patients with widespread pain, and not in those with localized pain such as myalgia or lumbal spinal or articular pain. One other possible explanation could be that the combination of depression and pain affects central inhibitory circuits, either through an opioid or serotonergic pathway, as reported by some authors. ${ }^{38,39}$ In the latter study, however, they only investigated using quantitative sensory testing.

\section{Disclosure}

The authors report no conflicts of interest in this work.

\section{References}

1. Ekselius L, Eriksson M, von Knorring L, Linder J. Comorbidity of personality disorders and major depression in patients with somatoform pain disorders or medical illnesses with long-standing work disability. Scand J Rehabil Med. 1997;29:91-96.

2. Linder J, Svensson O. The impact of pain and depression on assessment of rehabilitation need: a cross-sectional study in long-term sick-listed patients. Int J Rehabil Res. 2007;30:255-260.

3. Linder J, Schüldt Ekholm K, Brodda Jansen G, Lundh G, Ekholm J. Long-term sick-leavers with difficulty in resuming work: comparisons between psychiatric-somatic co-morbidity and monodiagnosis. Proceedings of the 7th Mediterranean Congress of Physical and Rehabilitation Medicine. Portoroze, Slovenia, Sept, Edizioni Minerva Medica, Turin, Italy; 2008:48-49.

4. Linder J, Schüldt Ekholm K, Brodda Jansen G, Lundh G, Ekholm J. Long-term sick-leavers with difficulty in resuming work: comparisons between psychiatric-somatic co-morbidity and monodiagnosis. Int $J$ Rehabil Res. 2009;32:20-35.

5. Linder J, Schüldt Ekholm K, Lundh G, Ekholm J. Long-term sickleavers with fibromyalgia: comparing their multidisciplinary assessed characteristics with those of others with chronic pain conditions and depression. J Multidiscip Healthc. 2009;2:23-37.

6. Fishbain DA, Cutler R, Rosomoff HL, Rosomoff RS. Chronic painassociated depression: antecedent or consequences of chronic pain? a review. Clin J Pain. 1997;13:116-137.

7. Bair MJ, Robinson R, Katon W, Kroenke K. Depression and pain co-morbidity. Arch Intern Med. 2003;163:2433-2445.

8. Garcia-Cebrian A, Gandhi P, Demyttenaere K, Peveler R. The association of depression and painful physical symptoms - review of the European literature. Eur Psychiatry. 2006;21:379-388.

9. Greden JF. Treating depression and pain. J Clin Psychiatry. 2009; 70:e16.

10. Mayer TG, Towns BL, Neblett R, Theodore BR, Gatchel RJ. Chronic widespread pain in patients with occupational spinal disorders: prevalence, psychiatric comorbidity, and association with outcomes. Spine (Phila Pa 1976). 2008;33:1889-1897.

11. Smith WR, Strachan ED, Buchwald D. Coping, self-efficacy and psychiatric history in patients with both chronic widespread pain and chronic fatigue. Gen Hosp Psychiatry. 2009;31:347-352.

12. Jain R. The implications of pain and physical symptoms in depression. J Clin Psychiatry. 2009;70:e19.

13. Suija K, Kalda R, Maaroos H. Patients with depressive disorder, their co-morbidity, visiting rate and disability in relation to self-evaluation of physical and mental health: a cross-sectional study in family practice. BMC Family Practice. 2009;10:38.

14. 4D Inc, 4D 2004, v 8.0.2. San Jose, CA: 4D Inc, 2005. Available at: http://www.4d.com/world. Accessed July 3, 2011.

15. JMP v 7 for Windows (2007). Cary, NC: SAS Institute Inc.

16. World Health Organization. International Classification of Functioning, Disability and Health. 1st ed. Geneva, Switzerland: WHO; 2001.

17. Svanborg P, Åsberg M. A new self-rating scale for depression and anxiety states based on the Comprehensive Psychopathological Rating Scale. Acta Psychiatr Scand. 1994;89:21-28.

18. Svanborg P, Ekselius L. Self-assessment of DSM-IV criteria for major depression in psychiatric out- and inpatients. Nord J Psychiatry. 2003; 57:291-296. 
19. Michael B. First, Miriam Gibbon. User's guide for the structured clinical interview for DSM-IV axis II personality disorders (SCID-II). Washington, DC: American Psychiatric Press; 1997.

20. Sullivan M, Karlsson J, Ware JE Jr. The Swedish SF-36 Health Survey - I. Evaluation of data quality, scaling assumptions, reliability and construct validity across general populations in Sweden. Soc Sci Med. 1995;41:1349-1358.

21. Ware JE, Kosinsky M, Dewey JE. How to Score Version 2 of the SF36 $\left({ }^{\circledR}\right.$ Health Survey. Lincoln, RI: Quality Metric Inc; 2000.

22. Landstad B, Schüldt K, Ekholm J, Bergroth A. Women at work despite ill health: diagnoses and pain before and after personnel support. A prospective study of hospital cleaners/home-help personnel with comparison groups. J Rehabil Med. 2001;33:216-224.

23. Åsberg M, Montgomery S, Perris C, Schalling D, Sedvall G. CPRS. The Comprehensive Psychopathological Rating Scale. Acta Psychiatr Scand. 1978;271(Suppl):5-27.

24. Ahrens C, Schiltenwolf M, Wang H. Health related quality of life (SF-36) in chronic low back pain and comorbid depression. Schmerz. 2010;24:251-256.

25. Bair MJ, Wu J, Damush T, Sutherland J, Kroenke K. Association of depression and anxiety alone and in combination with chronic musculoskeletal pain in primary care patients. Psychosom Med. 2008; 70:890-897.

26. Wang H, Ahrens C, Rief W, Schiltenwolf M. Influence of comorbidity with depression on interdisciplinary therapy: outcomes in patients with chronic low back pain. Arthritis Res Ther. 2010;12:R185.

27. Fuller-Thomson E, Nimigon-Young J, Brennenstuhl S. Individuals with fibromyalgia and depression: Findings from a nationally representative Canadian survey. Rheumatol Int. 2011. [Epub ahead of print].

28. Hall AM, Kamper SJ, Maher CG, Latimer J, Ferreira ML, Nicholas MK. Symptoms of depression and stress mediate the effect of pain on disability. Pain. 2011;152:1044-1051.

29. Reme SE, Tangen T, Moe T, Eriksen HR. Prevalence of psychiatric disorders in sick listed chronic low back pain patients. Eur J Pain. 2011. [Epub ahead of print].
30. Romera I, Fernández-Pérez S, Montejo AL, et al. Generalized anxiety disorder, with or without co-morbid major depressive disorder, in primary care: prevalence of painful somatic symptoms, functioning and health status. J Affect Disord. 2010;127:160-168.

31. Romera I, Montejo AL, Caballero F, et al. Functional impairment related to painful physical symptoms in patients with generalized anxiety disorder with or without comorbid major depressive disorder: post hoc analysis of a cross-sectional study. BMC Psychiatry. 2011;11:69.

32. Wong WS, Chen PP, Yap J, Mak KH, Tam BK, Fielding R. Chronic pain and psychiatric morbidity: a comparison between patients attending specialist orthopedics clinic and multidisciplinary pain clinic. Pain Med. 2011;12:246-259

33. Lautenbacher S, Spernal J, Schreiber W, Krieg JC. Relationship between clinical pain complaints and pain sensitivity in patients with depression and panic disorder. Psychosom Med. 1999;61:822-827.

34. Dickens C, McGowan L, Dale S. Impact of depression on experimental pain perception: a systematic review of the literature with meta-analysis. Psychosom Med. 2003;65:369-375.

35. Merskey H. Psychiatric patients with persistent pain. J Psychosom Res. 1965;9:299-309.

36. Burton AK, Tillotson KM, Main CJ, Hollus S. Psychosocial predictors in outcome in acute and subchronic low back trouble. Spine. 1995;20: $722-728$.

37. Lamb SE, Guralnik JM, Buchner DM. Factors that modify the association between knee pain and mobility limitations in older women: the women's health and aging study. Ann Rheum Dis. 2000;59:331-337.

38. Frew AK, Drummond PD. Stress-evoked opioid release inhibits pain in major depressive disorder. Pain. 2008;139:284-92

39. Klauenberg S, Maier C, Assion HJ. Depression and changed pain perception: hints for a central disinhibition mechanism. Pain. 2008;140: 332-343.
Journal of Multidisciplinary Healthcare

\section{Publish your work in this journal}

The Journal of Multidisciplinary Healthcare is an international, peerreviewed open-access journal that aims to represent and publish research in healthcare areas delivered by practitioners of different disciplines. This includes studies and reviews conducted by multidisciplinary teams as well as research which evaluates the results or conduct of such teams or

\section{Dovepress}

healthcare processes in general. The journal covers a wide range of areas and welcomes submission from practitioners at all levels, from all over the world. The manuscript management system is completely online and includes a very quick and fair peer-review system. Visit http://www.dovepress.com/testimonials.php to read real quotes from published authors. 